\title{
Influence of Mahaleb and Gisela 5 Rootstocks on the Growth of 'Biggareau Burlat' Sweet Cherry Cultivar
}

\author{
Monica PAL ${ }^{1 *}$, Viorel MITRE ${ }^{1}$, Andreea TRIPON ${ }^{1}$, Mihai LAZAR ${ }^{1}$, Tabita LISANDRU ${ }^{1}$ \\ Sabin MOLNAR ${ }^{1}$ \\ ${ }^{1}$ Department of Fruit growing, University of Agricultural Sciences and Veterinary Medicine, Cluj- \\ Napoca, Romania \\ *)Corresponding author, e-mail: pal.monicadiana@gmail.com
}

BulletinUASVM Horticulture 73(2) / 2016

Print ISSN 1843-5254, Electronic ISSN 1843-5394

DOI:10.15835/buasvmcn-hort:11955

\begin{abstract}
The influence of Prunus Mahaleb L. and 'Gisela 5' rootstocks on the growth of 'Biggareau Burlat' sweet cherry cultivar was evaluated in the environmental conditions of Cluj-Napoca city, in 2015, in a high-density plot (trees were planted at the distance of $4 \times 1.5 \mathrm{~m}$ ) with 1666 trees/ha, trained as spindle bush, with trellis system with drip fertirigation provided. The measurements were done in April, on 10 trees of the cultivar grafted on different rootstocks, in the $4^{\text {th }}$ year after planting. The trunk diameter growth was measured $5 \mathrm{~cm}$ above the grafting joint point, and the number and length of annual growth were also recorded (long, medium and spur fruiting branches) and tree height was calculated. After the first years of planting, 'Biggareau Burlat' grafted on 'Gisela 5' rootstock proved to be more vigorous than grafted on Prunus Mahaleb L., considering the total number of the medium and long branches per tree. 'Biggareau Burlat'/Gisela 5, compared to 'Biggareau Burlat'/P. Mahaleb significantly exceeded in the number of medium branches (4.7 in comparison with 3), number of long branches on the tree (17.2 comparing to 7.9), and the number of flower buds (74.7 compared to 41.3) and also the total length of annual tree branches.
\end{abstract}

Keywords: branches, growth, Prunus mahaleb L., rootstock, sweet cherry

\section{Introduction}

Sweet cherry is a fruit tree with a high economic value, because of the nutritive, commercial and technological characteristics of the fruits (Budan S. and Gradinariu G., 2000). In the last years, there has been manifested an important interest of cultivating new cultivars of sweet cherries, grafted on dwarf vegetative cherry rootstocks (Lang, 2001). This allowed developing high-density orchards with smaller vigour trees that are more productive and precocious (Andersen et al., 1999).

\section{Aims and objectives}

The main objective of this study was to investigate the influence of Prunus mahaleb $\mathrm{L}$. and 'Gisela 5' rootstocks on the growth parameters of
'Biggareau Burlat' sweet cherry cultivar, in the $4^{\text {th }}$ year after planting, in the eco-climatic conditions of Cluj-Napoca city, in 2015.

\section{Materials and methods}

This research has been carried out in the spring of 2015. The study took place in the fruitgrowing ecosystems of Steluța from Cluj-Napoca, in a high-density plot ( 4 x $1.5 \mathrm{~m}$ ) with 1666 trees/ ha, trained as spindle bush, provided with trellis system and drip fertirigation. Determinations regarding the influence of two different rootstocks, Prunus Mahaleb L. and 'Gisela 5', have been made for 'Biggareau Burlat' sweet cherry cultivar on: the tree height, the trunk diameter growth, number of long branches on the tree, number of medium 
Tab. 1. The influence of Prunus Mahaleb L. and 'Gisela 5' rootstocks on the growth of 'Biggareau Burlat' sweet cherry cultivar

\begin{tabular}{|c|c|c|c|c|c|c|c|c|}
\hline $\begin{array}{l}\text { Cultivar/ } \\
\text { Rootstock }\end{array}$ & $\begin{array}{l}\text { Tree height } \\
\text { (cm) }\end{array}$ & $\begin{array}{c}\text { Trunk } \\
\text { height } \\
\text { (cm) }\end{array}$ & $\begin{array}{c}\text { Trunk } \\
\text { diameter } \\
\text { (cm) }\end{array}$ & $\begin{array}{c}\text { Number of } \\
\text { medium } \\
\text { branches }\end{array}$ & $\begin{array}{l}\text { Length of } \\
\text { medium } \\
\text { branches } \\
\text { (cm) }\end{array}$ & $\begin{array}{c}\text { Number of } \\
\text { inflorescence } \\
\text { buds }\end{array}$ & $\begin{array}{c}\text { Number } \\
\text { of long } \\
\text { branches }\end{array}$ & $\begin{array}{c}\text { Length } \\
\text { of long } \\
\text { branches } \\
\text { (cm) }\end{array}$ \\
\hline $\begin{array}{l}\text { Burlat/ } \\
\text { Gisela } 5\end{array}$ & $\begin{array}{c}298,5 \pm \\
21,08\end{array}$ & $57,3 \pm 7,40$ & $5,36 \pm 0,48$ & $4,7 \pm 1,94$ & $22,04 \pm 3,82$ & $75,7 \pm 30,98$ & $17,2 \pm 4,28$ & $\begin{array}{l}58,26 \\
\pm 7,20\end{array}$ \\
\hline \multirow[t]{3}{*}{$\begin{array}{c}\text { Burlat/ } \\
\text { Mahaleb }\end{array}$} & $\begin{array}{c}300,8 \pm \\
20,02\end{array}$ & $\begin{array}{c}73,1 \\
\pm 17,80 \\
\end{array}$ & $4,38 \pm 0,88$ & $3 \pm 1,63$ & $21,79 \pm 3,19$ & $41,3 \pm 11,34$ & $7,9 \pm 2,68$ & $\begin{array}{l}57,26 \\
\pm 6,58 \\
\end{array}$ \\
\hline & $\mathrm{p}=0,805$ & $\mathrm{p}=0,018$ & $p=0,006$ & $p=0,048$ & $p=0,871$ & $\mathrm{p}=0,004$ & $p=0,000$ & $\mathrm{p}=0,750$ \\
\hline & $\mathrm{F}=0,062$ & $F=6,712$ & $F=9,395$ & $F=4,476$ & $F=0,026$ & $F=10,871$ & $\mathrm{~F}=33,770$ & $F=0,104$ \\
\hline
\end{tabular}

A.
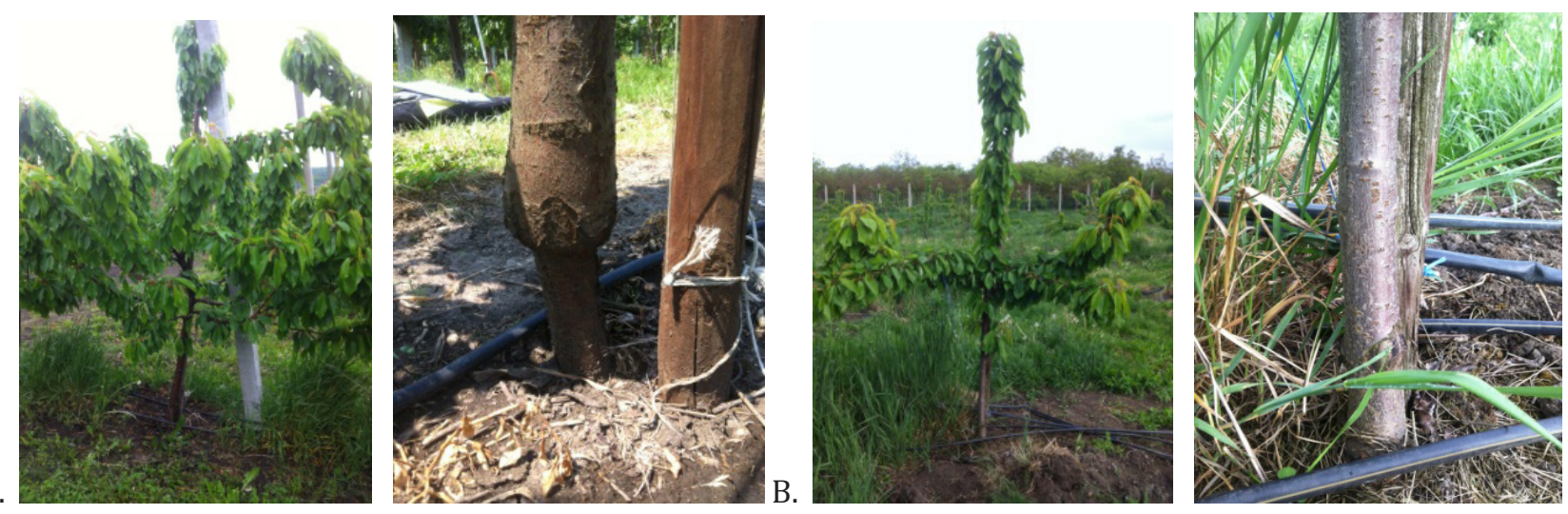

Fig. 1 Tree vigour and trunk diameter of 'Bigarreau Burlat' sweet cherry cultivar grafted on 'Gisela 5'(A) and 'Bigarreau Burlat' grafted on Prunus mahaleb (B.) in the $4^{\text {th }}$ year after planting

braches, number of flower buds, the lengths of medium and long branches. Ten experimental trees were selected per cultivar and the trunk diameter was measured with a caliper $5 \mathrm{~cm}$ above the grafting point, and the length of the branches was measured using a tape measure.

The statistical analyses were conducted using SPSS software version 18.0 (SPSS Inc. Chicago, IL, USA).

\section{Results and Discussion}

Regarding the vigour of the examined cultivars (Tab. 1), it could be remarked that 'Burlat'/'Gi 5' has registered the biggest increase in diameter growth of the trunk $(5.36 \mathrm{~cm})$, significantly distinct from 'Burlat'/Mahaleb (4.38 cm) (Fig.1), and the lowest value with a significant difference of trunk height (57.3 cm compared to $73.1 \mathrm{~cm}$ ). The biggest number of inflorescences per tree were counted for 'Burlat/'Gi 5' (75.7), followed by 'Burlat'/Mahaleb with 41.3 inflorescences/ tree. It can be observed in Tab. 1 that 'Burlat/'Gi 5' formed the highest number of long branches per tree (17.2) compared to 'Burlat'/Mahaleb (7.9) and the data collected showed a very significant interaction between the cultivars. The studies on the tree height, length of medium branches and long branches did not show any significant differences between the cultivars.

The means were compared using Duncan's Multiple Range Test, at $P \leq 0,05$. The interaction between cultivars and rootstocks was evaluated by selecting $\mathrm{P} \leq 0.0001, \mathrm{P} \leq 0.01$ and $\mathrm{P} \leq 0.05$ to determine significance. 


\section{Conclusion}

Analysing the growth parameters of 'Bigarreau Burlat' sweet cherry cultivar grafted on two different rootstocks, in the $4^{\text {th }}$ year after planting it can be concluded that compared to Mahaleb, Gisela 5 rootstock improved precocity being the most efficient rootstock for sweet cherry trees in high-density systems.

\section{REFERENCES}

1. Andersen RL, Robinson TL and Lang GA (1999). Managing the Gisela cherry rootstocks, New York Fruit Quarterly 7(4):19-22.

2. Budan S, Grădinariu G (2000). Cherry tree, Editura Ion Ionescu de la Brad, Iaşi.

3. Lang GA (2001). Intensive sweet cherry orchard systemsrootstock, vigor, precocity, productivity, and management. Compact Fruit Tree, 34(1), 23-26. 